\title{
Robots vs. Monkeys: Intellectual Property Rights of Non-Human Creators
}

Tiffany Li*, Charles M. Roslof**

Abstract

A fundamental tenet of i intellectual property law is that it is beneficial to
give creators some measure of ownership over their creative or scientific give cre
works.

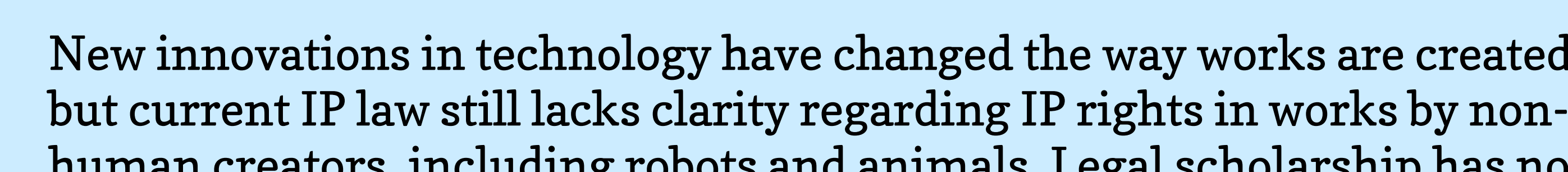
human creatotss, including robots and animals. Legal scholarship has not
reached a consensus on how principles of intelectual property can or
should be applied, broadly, to works of non-human creators. In this study, we explore possible directions for the future of IP law,
specificilly involving works by nonnhuman creators. We look a thehe (scant)
legal precedent in these two realms and provide comparisons of the legal legal precedent in these two realms and provide comparisonn of the legal
precedent and academic discourse surrounding each topic. Based on findings from this comparative analysis, we offer potential
recommendations and future paths of research for the field of IP rights of non-human creators.

Research and Policy Questions (RPQs) How does current I P law treat works and inventions by non-human
creators? How the should the law treat such works and inventions, now and in
the future?

Introduction: IP Theory

How we answer the RPQs depends in part on an understanding of the heoretical justification for IP protection, at least for copyright and patent
the Incentive Theory. The idea is that society as a whole benefits when W works and inventions are created, so the legal system should monopoly rights over their creations better enabables to them to make money off of those creations, and thus incentivizes them to treate more
Limiting those monopoly rights (such as with term limits allows the Limiting those monopoly rights (such as
public to still benefit from the creations.

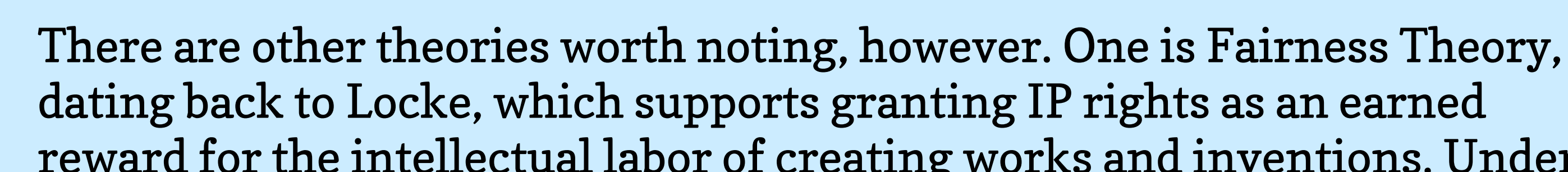
Fairness Theory, people deserve to own and control their creations becaus they did the work to create them. And if multiple people contribute to a
creation, each deserves IP rights in proportion to the work they did to create

Finally, there is Personality Theory, which supports granting IP rights
because of the investment of one's self one makes in creating an

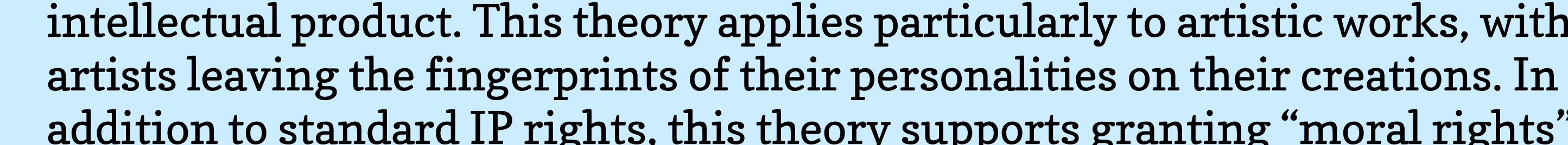
addition to standard IP rights, this theory supports granting "moral rights"
as can be found in some jurisdictions' copyright law. These rights are

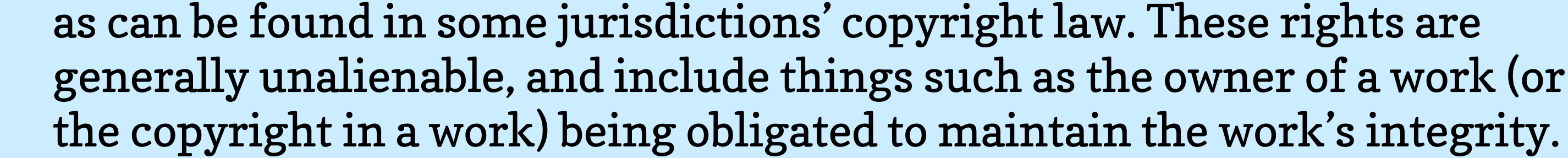
Theories of IP can be guides to find answers to questions on the frontier of
IP law. They provide direction and structure, and while they sometimes point toward different answers they can also coxist. While Incentive
Theory is the predominant basis for most of IP law and policy, there are still provisions of IP statutes that are more firmly grounded in the othe
theories.

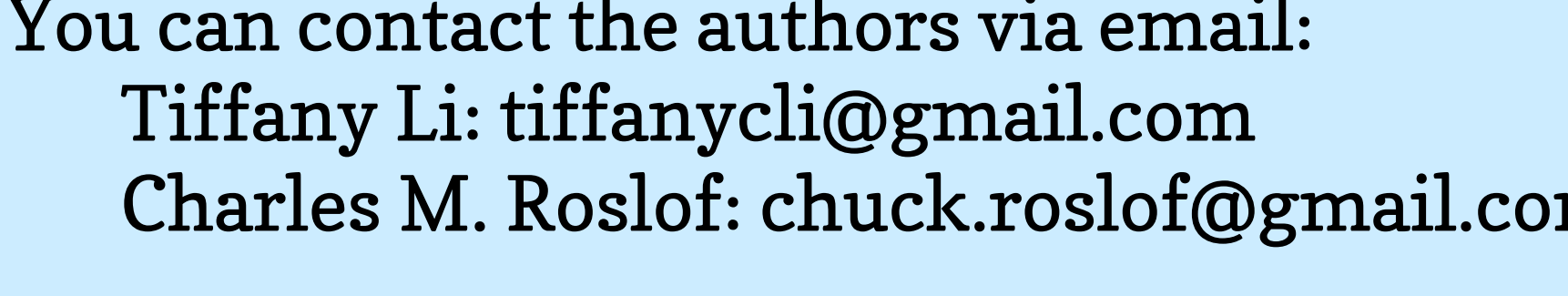

A PDF version of this poster is available here: http://ssrn.
com/abstract=2756245.

Acknowledgments

We would like to thank our wonderfully supportive colleagues at the
Wikimedia Foundation. Wikimedia Foundation.

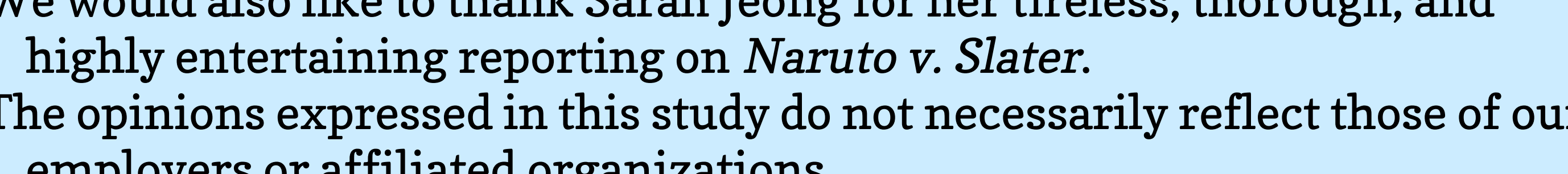

\begin{tabular}{|c|}
\hline ghts \\
\hline 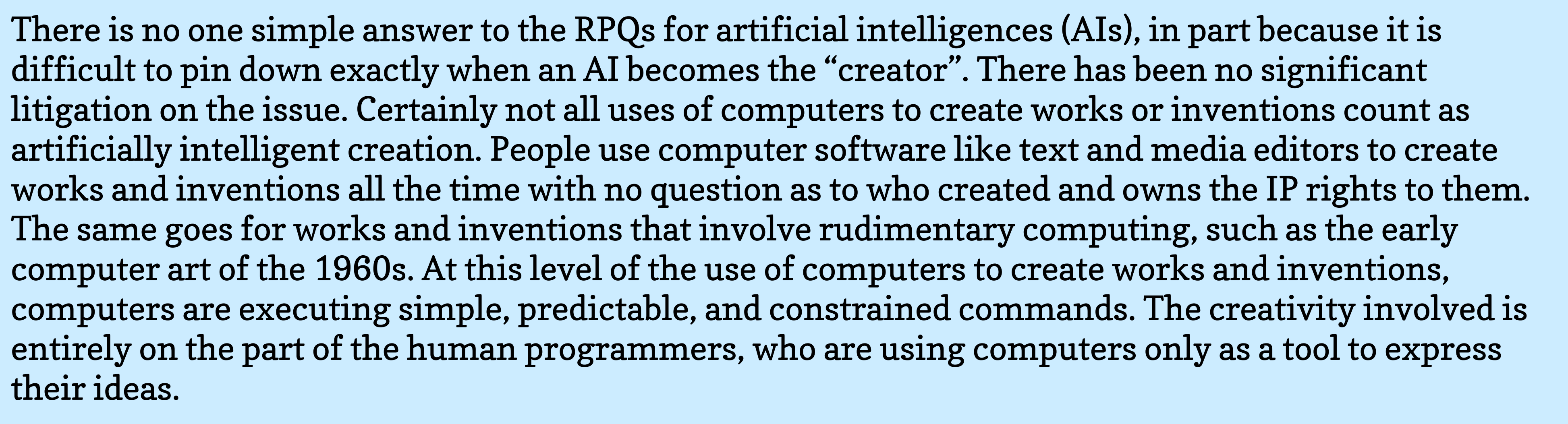 \\
\hline 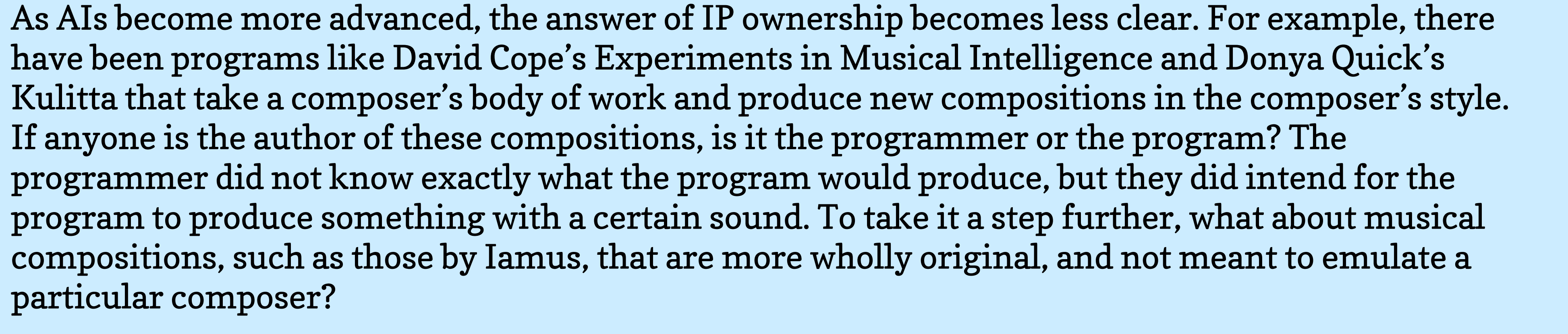 \\
\hline 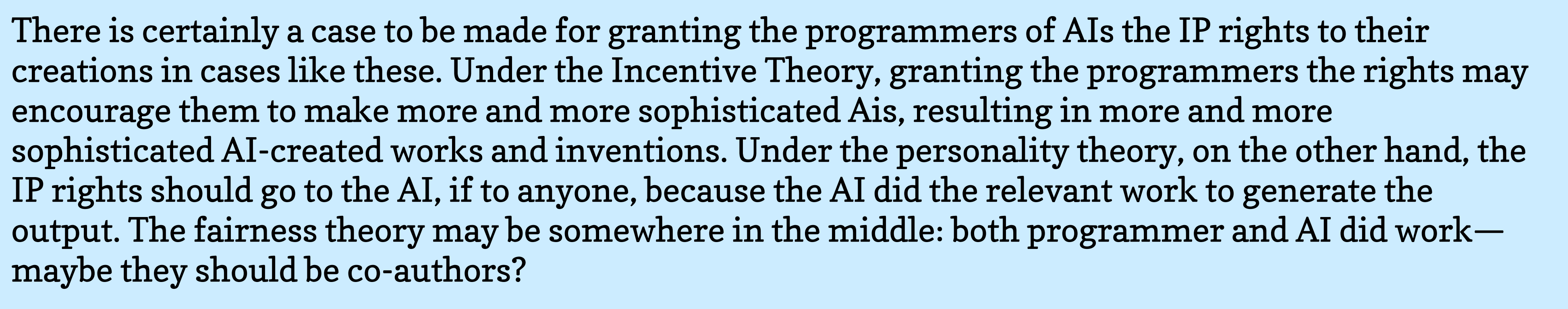 \\
\hline 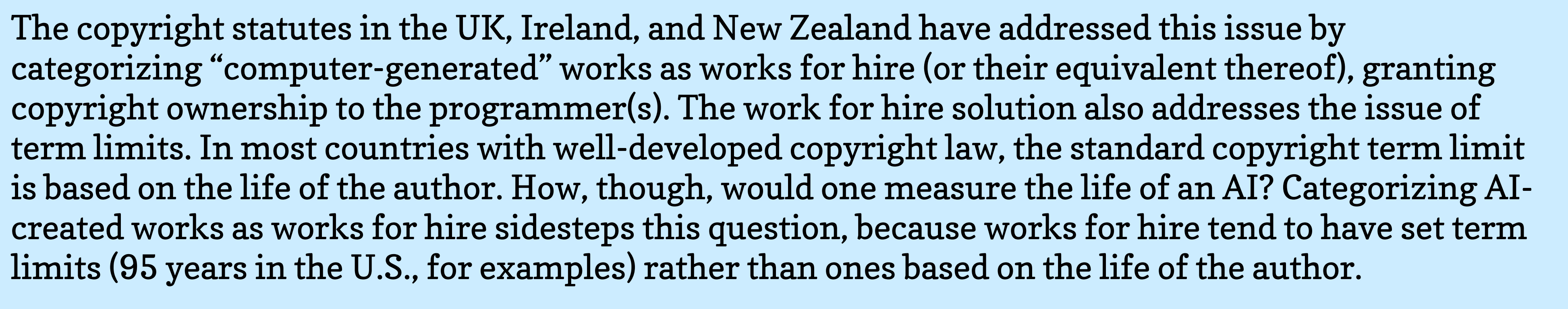 \\
\hline 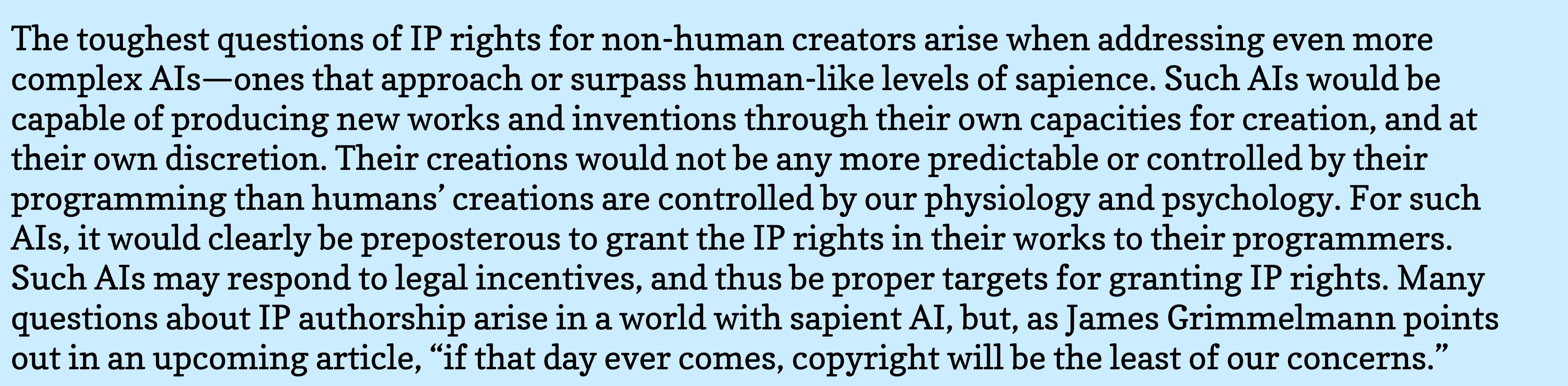 \\
\hline
\end{tabular}

Animal Intellectual Property Rights

Precedent regarding intellectual property rights for animals largely stems from what is now widely known
as the case of the "monkey selfie."

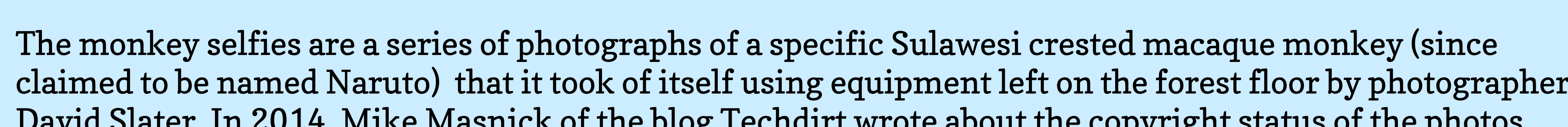

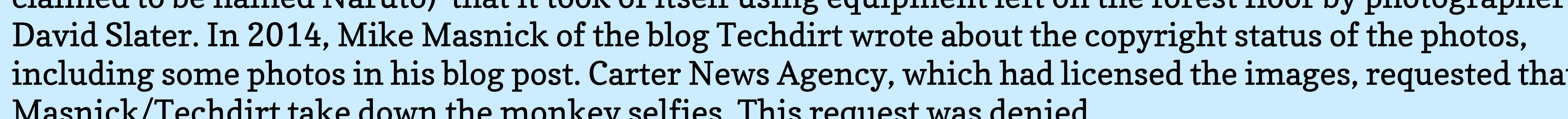

A selection of these photoss was also uploaded to Wikimedia Commons, an online media filie repositiory for
public domain and freely-licensed educational media content. The Wikimedia Foundation, the nonprofit organization behind Wikimedia Commonss, also denied a takkedown request. In a statement from the
Wikimedia Foundation, a spokesperson sadid "Because the monkey took the picture, it means that there was
no o one on whom to bestow copyright, so the image falls into the public domain." This kerfuffle raised the issue of whether copprightl law allows a monkey (or any animall to be the author of
hid own the rights to a hotog gaph (or any workl). Slater argued that he should own the copyright in the

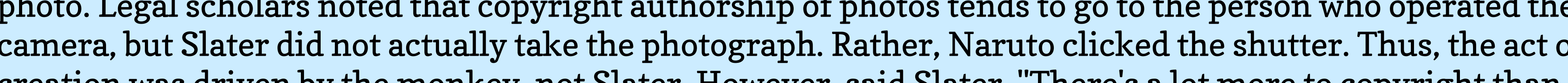
creation was driven by the monkey, not Slater. However, said Slater, "There's a lot more to copyright than
who pushes the trigger on the camera. I set up the shot. I was behind all the components in taking that who pushes the trigger on the camera. I set up the shot, I was behind all the components in taking that
image." This raises a separate but related issue of whether a human can own copyright in an image
produced by animals using the humann's equipment or under the human's directions.

Neither of these issues has been resolved in current legal precedent. In 2014 , the US Copyright Office
released guidance in the Commendium of US Copyright office Practices, Third Edition. The Copyright Office

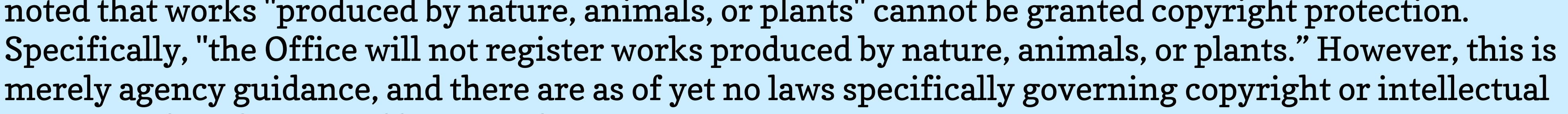
merely agency guidance, and there are as of yet no laws specifically governing copyright or intellectual
property of works created by animals.

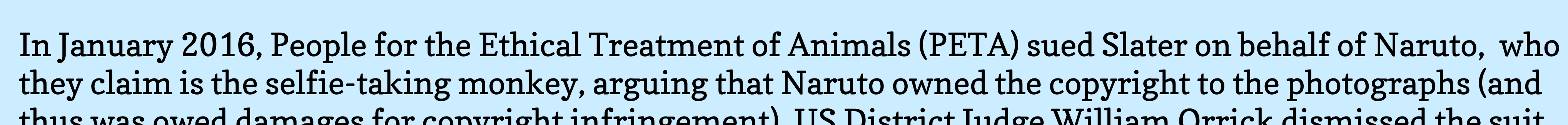

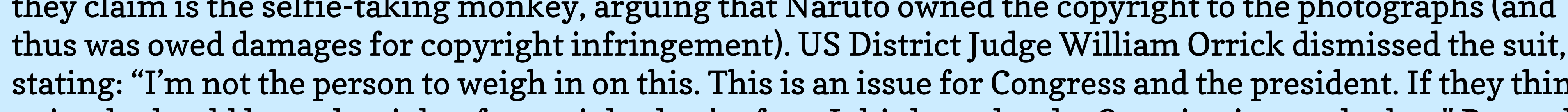

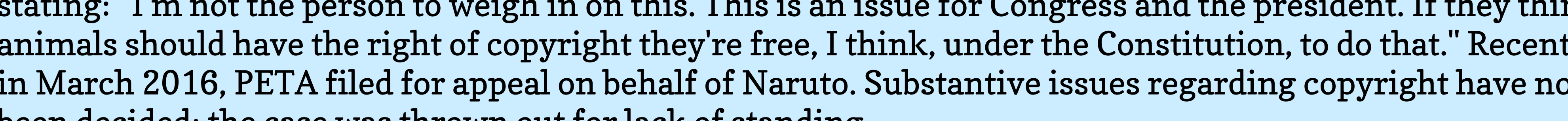

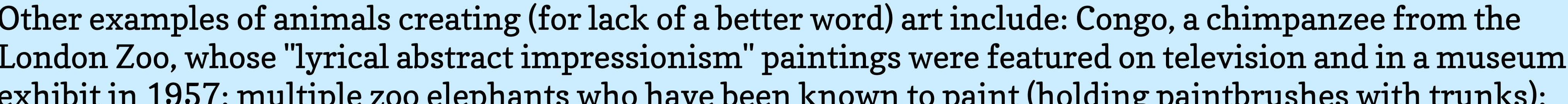
exhibit in 157 ; multiple zoo elephants who have been known to paint holding paintbrushes with trut
and a movi filmed by chimpanzees. It has not as of yet been determined whether these animals are
exhibiting creativity on par with humans in their "creation" of what some could call "art."

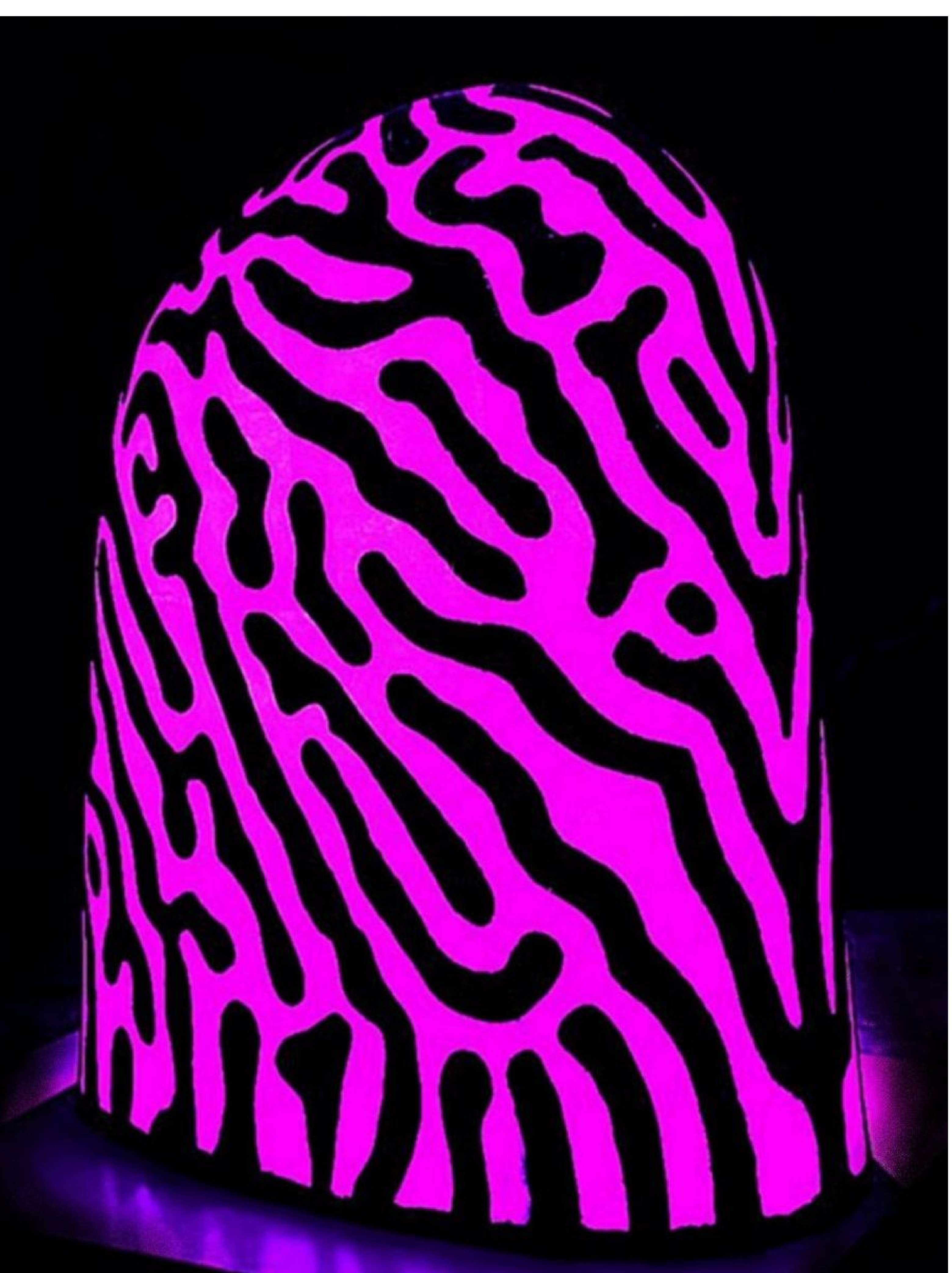

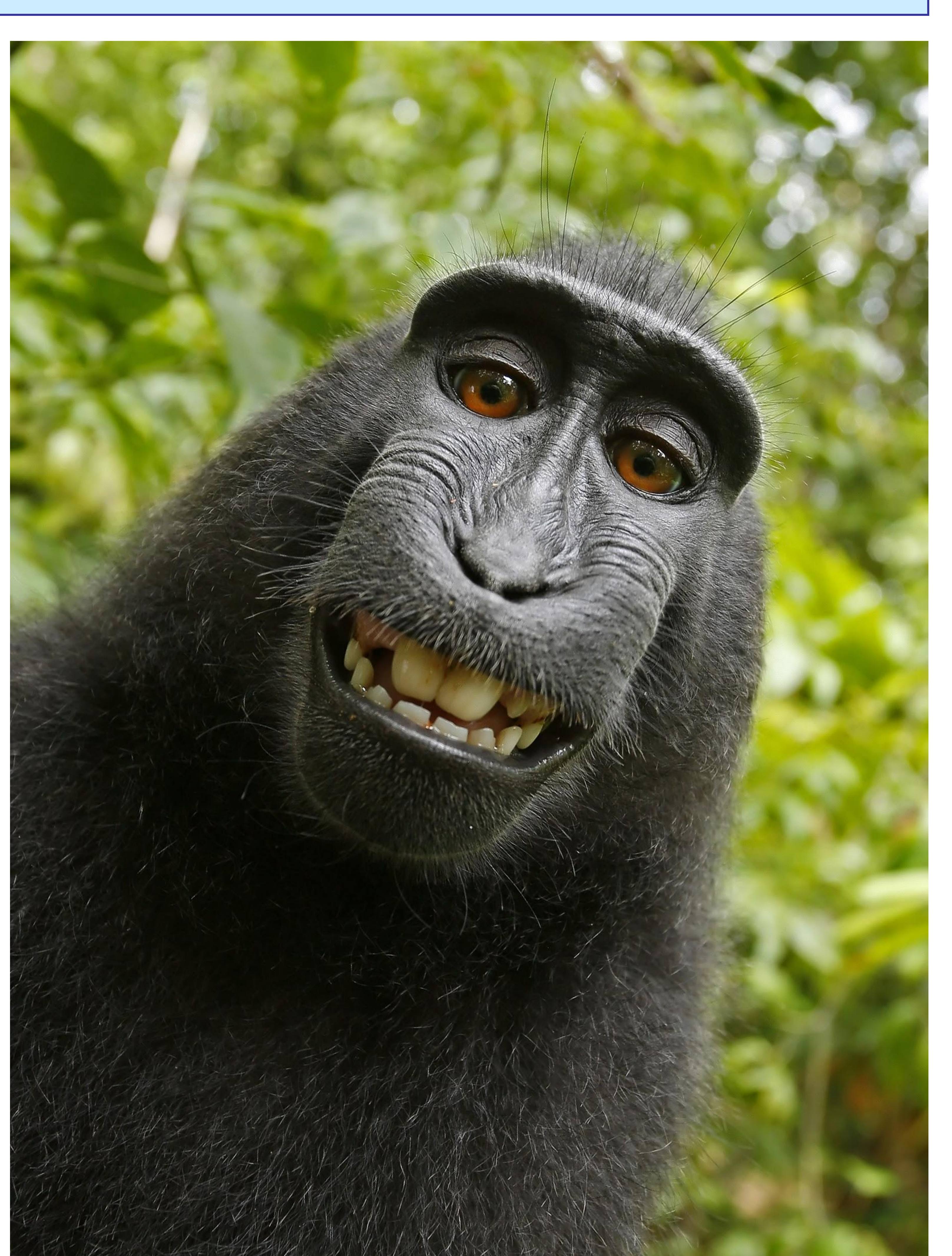

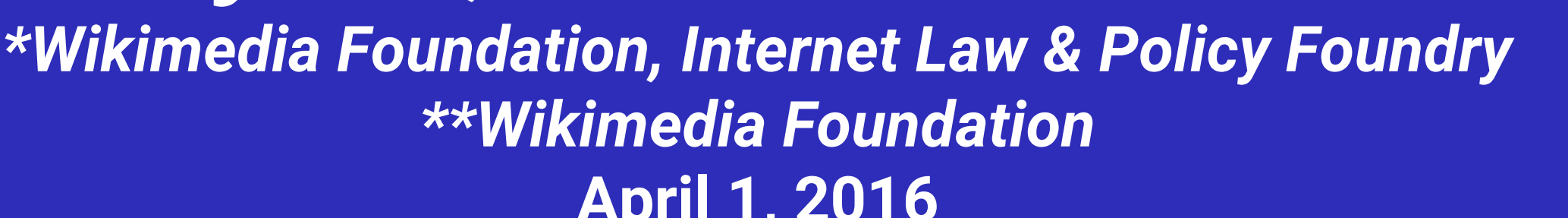

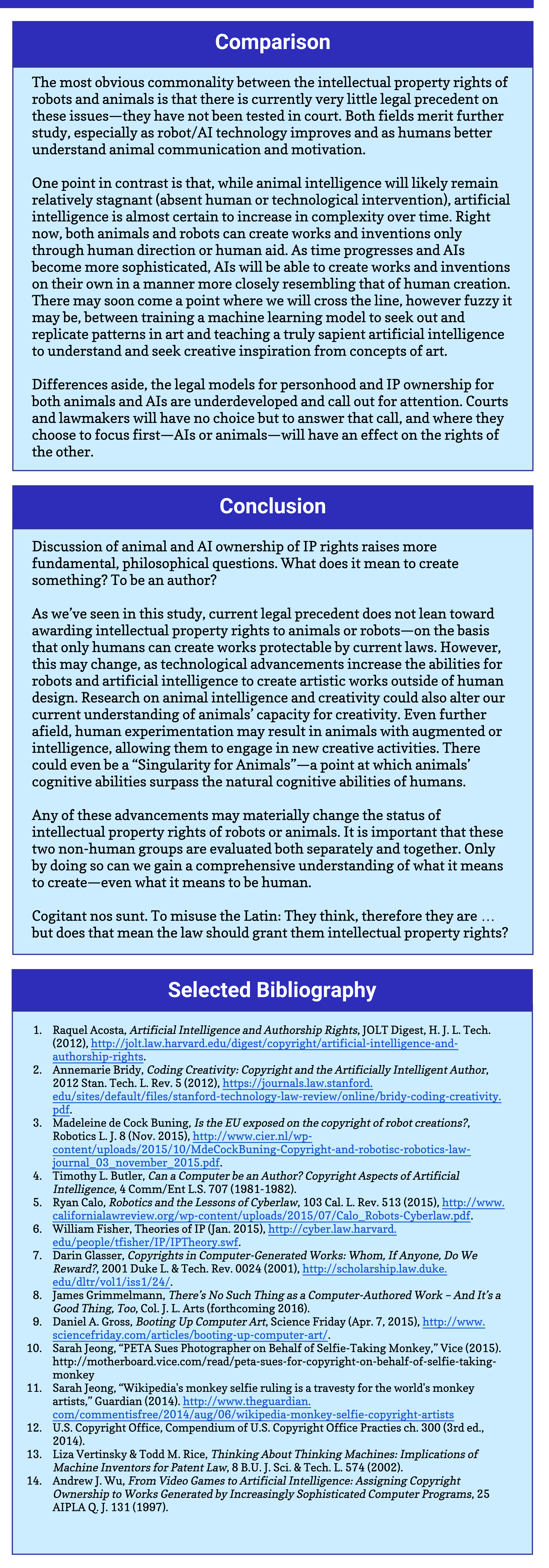

